\title{
Biochemical identification of new proteins involved in splicing repression at the Drosophila P-element exonic splicing silencer
}

\author{
Lucas Horan, ${ }^{1,4}$ Jiro C. Yasuhara, ${ }^{1,4}$ Lori A. Kohlstaedt, ${ }^{2}$ and Donald C. Rio ${ }^{1,2,3}$ \\ ${ }^{1}$ Department of Molecular and Cell Biology, University of California at Berkeley, Berkeley, California 94720, USA; ${ }^{2}$ California \\ Institute for Quantitative Biosciences (QB3), University of California at Berkeley, Berkeley, California 94720, USA; ${ }^{3}$ Center for \\ RNA Systems Biology, University of California at Berkeley, Berkeley, California 94720, USA
}

Splicing of the Drosophila P-element third intron (IVS3) is repressed in somatic tissues due to the function of an exonic splicing silencer (ESS) complex present on the 5' exon RNA. To comprehensively characterize the mechanisms of this alternative splicing regulation, we used biochemical fractionation and affinity purification to isolate the silencer complex assembled in vitro and identify the constituent proteins by mass spectrometry. Functional assays using splicing reporter minigenes identified the proteins hrp36 and hrp38 and the cytoplasmic poly(A)binding protein PABPC1 as novel functional components of the splicing silencer. hrp48, PSI, and PABPC1 have highaffinity RNA-binding sites on the P-element IVS3 5' exon, whereas hrp36 and hrp38 proteins bind with low affinity to the P-element silencer RNA. RNA pull-down and immobilized protein assays showed that hrp48 protein binding to the silencer RNA can recruit hrp36 and hrp38. These studies identified additional components that function at the P-element ESS and indicated that proteins with low-affinity RNA-binding sites can be recruited in a functional manner through interactions with a protein bound to RNA at a high-affinity binding site. These studies have implications for the role of heterogeneous nuclear ribonucleoproteins (hnRNPs) in the control of alternative splicing at cis-acting regulatory sites.

[Keywords: pre-mRNA splicing; exonic splicing silencers; splicing repression]

Supplemental material is available for this article.

Received July 15, 2015; revised version accepted October 7, 2015.

Alternative premessenger RNA (pre-mRNA) splicing is a major mechanism for regulating gene expression in higher eukaryotic organisms. For example, deep sequencing analyses estimate that as much as $99 \%$ of the human genes are subject to alternative splicing (Pan et al. 2008; Wang et al. 2008; Barbosa-Morais et al. 2012; Merkin et al. 2012). Alternative splicing functions to increase proteomic diversity among organisms with similar numbers of genes and can affect the primary structures of the encoded proteins by inserting, deleting, or replacing stretches of amino acids. Alternatively spliced mRNA isoforms can encode proteins that have completely different or even opposite biological functions. Consistent with the idea that the alternatively spliced mRNA products of each gene have distinct functions, alternative splicing patterns for many genes have been evolutionarily conserved (Yeo et al. 2005). Recent studies have shown that mutations in both

\footnotetext{
${ }^{4}$ These authors contributed equally to this work.

Corresponding author: don_rio@berkeley.edu

Article is online at http://www.genesdev.org/cgi/doi/10.1101/gad.268847. 115 .
}

cis-acting RNA regulatory elements and trans-acting splicing factors can play a role in human diseases (Cooper et al. 2009; Padgett 2012; Lee and Rio 2015) such as cancer (Liu and Cheng 2013; Scott and Rebel 2013; Zhang and Manley 2013). Alternative splicing has great potential in a clinical setting as a diagnostic tool (Liu and Cheng 2013), a therapeutic tool (Singh and Cooper 2012), and a direct target of therapeutic treatments (Bonnal et al. 2012). Development of reliable therapeutic regimes will require detailed understanding of the biochemical mechanisms underlying specific alternative splicing events.

Pre-mRNA splicing is carried out in the nucleus by the spliceosome, which consists of five small nuclear ribonucleoprotein (snRNP) complexes (termed U1, U2, U4, U5, and U6) as well as a number of non-snRNP splicing factor proteins. Molecular organization and function of the

(C) 2015 Horan et al. This article is distributed exclusively by Cold Spring Harbor Laboratory Press for the first six months after the full-issue publication date (see http://genesdev.cshlp.org/site/misc/terms.xhtml). After six months, it is available under a Creative Commons License (Attribution-NonCommercial 4.0 International), as described at http:// creativecommons.org/licenses/by-nc/4.0/. 
spliceosome in the cycle of the splicing reaction have been analyzed extensively (Wahl et al. 2009). In contrast, how active spliceosomes are recruited to different sites on a pre-mRNA to execute alternative splicing patterns is still poorly understood. Generally, it is known that a number of nonspliceosomal RNA-binding proteins bind to defined sites in the pre-mRNA that function to promote (exonic and intronic splicing enhancers) or prevent (exonic or intronic splicing silencers) the recruitment of the spliceosomal snRNPs to specific sites in the pre-mRNA (Black 2003; Lee and Rio 2015). Given that there is a finite number of nuclear RNA-binding proteins (no more than a few hundred in Drosophila [Lasko 2000] and humans), it appears likely that each alternative splicing event is mediated by the combinatorial action of multiple RNAbinding proteins. Indeed, genome-wide studies have supported the idea of combinatorial control of sets of splice events by overlapping sets of proteins in Drosophila and humans (Blanchette et al. 2009; Huelga et al. 2012; Lee and Rio 2015).

The P-element transposon in Drosophila has provided an interesting paradigm of tissue-specific regulation of alternative splicing (Rio 2002; Majumdar and Rio 2015). The full-length $\mathrm{P}$ element contains a gene that consists of four exons and three introns. Transposition of the P element occurs only in the germline and not in somatic tissues, and this tissue specificity is regulated at the level of pre-mRNA splicing (Laski et al. 1986). In the germline, all three introns are removed in a small fraction of the P-element pre-mRNA, and the resulting mRNA encodes the $87-\mathrm{kDa}$ transposase protein that catalyzes P-element mobility (Rio et al. 1986; Roche et al. 1995). In somatic tissues, in contrast, splicing of the third intron (IVS3) is completely blocked, resulting in intron retention. The intron-retained form of the mRNA contains an in-frame translation termination codon to encode a $66-\mathrm{kDa}$ protein that functions as a repressor of transposition (Misra and Rio 1990).

Previous studies have provided insights into the mechanism for the somatic repression of the P-element IVS3 splicing. The splicing inhibition in somatic cells is mediated by an exonic splicing silencer (ESS) element upstream of the P-element IVS3. This critical cis-regulatory RNA element resides within 37 nucleotides (nt) of exonic sequence immediately $5^{\prime}$ to IVS3 and is sufficient to recapitulate the somatic splicing repression in vitro (Siebel and Rio 1990) and in vivo (Laski and Rubin 1989). Mutations in the exonic silencer sequence relieved the repression (Chain et al. 1991; Siebel et al. 1992). Within this regulatory sequence are two pseudo-5' splice sites, termed F1 and F2 (Siebel et al. 1992). The F1 site binds to U1 snRNP, which is also accompanied by the formation of a multiprotein complex over a broader region of the RNA, including the F2 site. Spliceosomal U1 snRNP bound to the F1 site is incapable of initiating splicing at the site, and the formation of the silencer complex sterically prevents the "accurate" $5^{\prime}$ splice site of IVS3 from binding another U1 snRNP, hence blocking splicing (Siebel et al. 1992). A series of in vitro UV protein-RNA cross-linking experiments showed that at least several proteins, including those that have approximate molecular weights of 97, 65,50 , and $40 \mathrm{kDa}$, can be bound to the $5^{\prime}$ exon RNA fragment and form complexes with distinct mobilities in the native gels (Siebel and Rio 1990; Chain et al. 1991; Siebel et al. 1992). Two of these proteins were identified. The 97$\mathrm{kDa}$ protein was identified as PSI (Siebel et al. 1994) and was shown to directly interact with the U1 snRNP and assist U1 snRNP binding to the F1 site (Labourier et al. 2001). The $\sim 50-\mathrm{kDa}$ protein was identified as hrp48, which binds the F2 site (Siebel et al. 1994). There is compelling evidence that PSI and hrp48 are bona fide regulators of IVS3 splicing repression. Depletion of functional PSI protein activated IVS3 splicing in vitro (Siebel et al. 1994, 1995) and in vivo (Adams et al. 1997), and ectopic expression of PSI in the germline repressed IVS3 splicing (Adams et al. 1997). IVS3 splicing was also activated somatically in the hrp48 mutant flies (Hammond et al. 1997). PSI is absent from the female germline (Siebel et al. 1995), which accounts for a partial loss of IVS3 splicing repression in the germline. In contrast, hrp48 is expressed in both somatic and germline tissues (Siebel et al. 1995). hrp48 belongs to a family of proteins called heterogeneous nuclear RNPs (hnRNPs), which are ubiquitously expressed and generally known to associate with nascent pre-mRNA transcripts (Dreyfuss et al. 1993; Black 2003; Lee and Rio 2015). Previous studies had also implicated additional proteins in the function of the P-element ESS (Siebel et al. 1992). However, the identities of the other proteins bound to the $5^{\prime}$ exon RNA besides PSI and hrp48 and whether and how these proteins participate in the alternative splicing regulation have remained unknown.

In the present study, we took a biochemical approach to assemble, isolate, and characterize the P-element splicing silencer complex. First, the P-element IVS3 splicing silencer complex was assembled in vitro on the P-element silencer RNA, fractionated by gel filtration chromatography, and affinity-purified using biotinylated RNA. Second, the proteins associated with the isolated complex were identified by mass spectrometry, and a list of proteins that were reproducibly detected in multiple experiments was defined. Third, the identified proteins were individually tested by RNAi for their effects on IVS3 splicing repression in vivo using splicing reporter minigenes. Among all of the proteins tested, only RNAi of hrp36, hrp38, and the cytoplasmic poly(A)-binding protein PABPC1 resulted in the activation of IVS3 splicing in somatic cells, as assayed by RT-PCR, suggesting that these proteins are functionally involved in the regulation of the P-element alternative splicing. Biochemical assays with purified recombinant proteins showed that hrp48, PSI, and PABPC1 showed high-affinity RNA binding to the P-element silencer RNA, whereas hrp36 and hrp38 showed low-affinity binding, consistent with previous SELEX data (Blanchette et al. 2009). Finally, using biotinlyated RNA and immobilized protein pull-down assays, we found that the hrp48 binding to the P-element RNA can recruit hrp36 and hrp38 to the P-element RNA, explaining how they can be found in the silencer complex. These studies identified new functional components 
involved in the P-element somatic splicing repression and provide general insights into how proteins with low-affinity RNA-binding sites may nonetheless function in alternative splicing regulation as part of a multiprotein RNP complex formed on an ESS element.

\section{Results}

\section{Purification of the P-element splicing silencer complex}

To isolate and identify the proteins that assemble on the P-element IVS3 5' exon silencer RNA to mediate splicing repression, we synthesized a 69-nt RNA containing the wild-type P-element $5^{\prime}$ exon sequence and the first $13 \mathrm{nt}$ of IVS3. The same or similar RNA fragments were used in the previous studies to demonstrate the PSI, hrp48, and U1 snRNP binding (Siebel and Rio 1990; Chain et al. 1991; Siebel et al. 1992, 1994). For comparison, a mutant version (L456) of the same RNA fragment was synthesized in which the critical cis-elements containing the F1 and F2 sites are mutated (Chain et al. 1991). Previous studies have shown that this mutation disrupts splicing silencer function in vivo (Chain et al. 1991). One of the key components of the splicing silencer complex is the inactive U1 snRNP bound to the F1 pseudo-5' splice site. To prevent U1 snRNP binding to the accurate IVS3 5' splice site, the IVS3 $5^{\prime}$ splice site was mutated in both the wild-type and L456 substrate RNAs used in these experiments (Siebel et al. 1992). The RNAs were also labeled with biotinylated UTP and $\alpha^{32}$ P-UTP. These RNAs were incubated with Drosophila somatic Kc cell nuclear extract to allow the assembly of the RNP complexes, which were then subjected to size fractionation on a Sephacryl S-500 gel filtration column (Fig. 1A). Although we only intended to use the S-500 column for separating the RNPs from the free RNAs and free proteins and did not necessarily expect it to resolve distinct RNPs, we ob- served that, in most experiments, the positions of the ${ }^{32} \mathrm{P}$ peaks were shifted by one or two fractions between the wild-type RNA and L456 RNA experiments (Fig. 1A). The direction of the shift was consistent with the idea that the wild-type RNA forms a larger complex due to the incorporation of U1 snRNP. We also performed fractionation experiments using glycerol density gradient centrifugation, and, here again, the apparent size shift between complexes formed on wild-type and mutant P-element silencer RNAs was also reproducible (Fig. 1B).

The peak fractions from the gel filtration column were pooled and incubated with NeutrAvidin resin to retrieve the biotinylated RNP complexes. In pilot experiments, we tested a few different avidin and streptavidin beads and found that only NeutrAvidin beads had sufficiently low levels of nonspecific protein binding (data not shown). The bound complexes were eluted with urea and formic acid for mass spectrometry. When small portions of the eluates were analyzed by SDS-PAGE, a number of proteins were visualized by silver staining (Fig. 1C). Some proteins were evidently enriched on either the wild-type or L456 RNA, while other proteins appeared to be present at similar levels on both the wild-type and L456 RNAs. Enrichment of the PSI and hrp48 proteins on the wild-type RNA compared with the mutant L456 RNA was confirmed by immunoblotting (Fig. 1D), demonstrating the validity of the biotin affinity purification approach. The rest of the eluates were digested with trypsin and subjected to multidimensional protein identification technology (MudPIT) liquid chromatography-tandem mass spectrometry (LC-MS/MS) for protein identification. We initially intended to compare the lists of proteins detected in the wild-type RNA experiment and the L456 RNA experiment and subtract the latter from the former to identify a set of proteins that are specifically bound to the wildtype RNA. However, this strategy was complicated by the fact that our mass spectrometry sample preparation
A
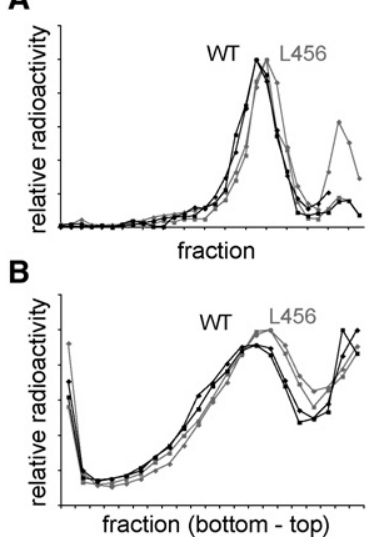

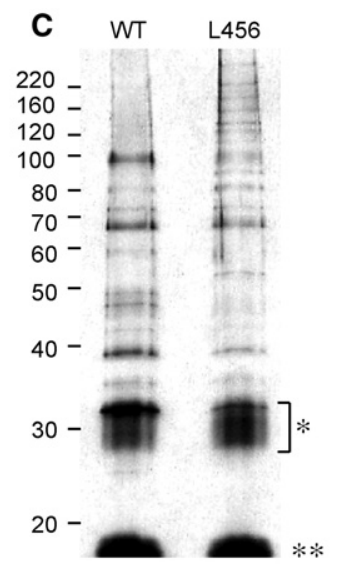

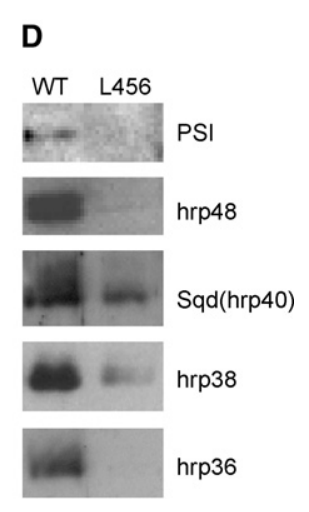

Figure 1. Purification of the P-element splicing silencer complex. (A) Sephacryl S-500 gel filtration fractionation profile of the P-element $5^{\prime}$ exon RNP complexes assembled in vitro. Experiments carried out with the wild-type RNA are shown in black, and those carried out with L456 RNA are shown in gray (two experiments each). The RNAs were labeled with $\alpha-{ }^{32} \mathrm{P}-\mathrm{UTP}$, and the $Y$-axis shows the radioactivity of the fractions normalized at the highest point. The second peak at the far right presumably corresponds to naked or degraded RNA. (B) The same in vitro assembled RNP complexes fractionated in the glycerol density gradients. $(C)$ SDS-PAGE and silver staining of the proteins bound to the P-element 5' exon RNAs. The positions of the size markers are shown at the left. The smear marked with the asterisk likely contains NeutrAvidin molecules, which are known to leach under harsh elution conditions, according to the manufacturer. The double asterisk corresponds to the RNase A added after elution. (D) Immunoblot of the proteins bound to the P-element $5^{\prime}$ exon RNAs. Equal volumes of the eluted samples were subjected to SDS-PAGE, blotted, and probed with specific antibodies against the proteins indicated at the right. Note that the Sqd (hrp40) immunoblot had been probed previously with anti-hrp36 and stripped before being reprobed with anti-Sqd, but there was some residual signal from the anti-hrp36 due to incomplete stripping. 
was not optimized for quantitative analysis, and the number of the identified peptides and proteins varied substantially between different purifications and peptide analyses (e.g., 19 proteins in one experiment and 79 in another). Nonetheless, using two different strategies for quantitative ion counting and normalization to a protein (GLO) found on both RNAs led to the identification of several proteins (hrp48, PSI, hrp36, hrp38, and PABPC1) that were enriched on the wild-type RNA (Supplemental Figs. 1,2). It is possible that some RNA-binding proteins, especially hnRNPs, may be capable of binding to both the wild-type and L456 RNAs and still play a key role in the context of a specific complex; for example, the hrp48 protein, where immunoblotting clearly showed significant enrichment on the wild-type RNA (Fig. 1D), and its role in IVS3 splicing repression has been previously established (Siebel et al. 1994; Hammond et al. 1997), yet detectable levels of hrp48 peptides were also found in samples using the L456 mutant RNA. Quantitative analysis indicated that hrp48 was enriched on the wild-type RNA versus the L456 RNA (Supplemental Figs. 1,2), consistent with the immunoblotting results (Fig. 1D). We chose to focus our efforts on seeking proteins that showed reproducible binding to the wild-type RNA rather than looking for differentially bound proteins between the wild-type and L456 RNAs. Toward this end, we repeated the biotin affinity purification experiments three more times using the wild-type RNA. Additionally, to obtain a mass spectrometry data set using an independent purification approach, we also performed an experiment in which the wild-type RNA was tagged with a PP7 RNA hairpin (Lim et al. 2001), and the RNP complexes were retrieved by binding recombinant MBP-PP7 protein and amylose resin. In our subsequent analyses, we focused our efforts on those proteins that were identified in at least two of these experiments. Fifty-nine proteins met this criterion (Supplemental Table 1), and 30 annotated RNAbinding proteins were selected for further analysis using RNAi with a splicing reporter assay (see below). As might be expected for the use of RNA affinity purification, the majority of the proteins identified here have an RNAbinding or nucleic acid-binding function according to the FlyBase annotation (Tweedie et al. 2009). Moreover, the RNA used in these experiments is only $69 \mathrm{nt}$, and, because of the large pore size of the Sephacyl S-500 column, we believe it is possible that there may be multiple complexes in the large gel filtration peaks or that some proteins are held in the complex by protein-protein interactions and do not make direct RNA-protein interactions, which might explain the large number of proteins identified by mass spectrometry. As noted above, two methods of quantitation (ion counting) of the mass spectrometry data indicated that some of the proteins that we later found to be functionally required for splicing repression were in fact enriched on the wild-type versus L456 mutant RNA (Supplemental Figs. 1,2). The hrp48 and PSI proteins were included on the list, and so were seven of the 10 protein components of U1 snRNP (Labourier et al. 2001). Two other small common Sm snRNP proteins, SmE and $\mathrm{SmF}$, were identified in only one experiment each. These data indicate that the splicing silencer complex was successfully isolated based on known protein components, and all proteins on the list besides hrp48, PSI, and U1 snRNP are new candidates for possible functional components of the silencer complex.

Use of RNAi and reporter minigenes to functionally validate the involvement of mass spectrometryidentified proteins in P-element IVS3 splicing repression

Conceptually, the proteins identified by mass spectrometry can be divided into three classes: (1) those that are an essential part of the complex and participate in the splicing silencer activity, (2) those that are part of the complex but have no roles in the splicing repression per se, and (3) those that have affinity for the $5^{\prime}$ exon RNA or for other proteins bound to it in vitro but have no biological relevance. To identify proteins that play a functional role in splicing, we wanted to determine whether splicing of IVS3 is activated using an IVS3 minigene splicing reporter under conditions in which somatic cells are individually depleted of each of these candidate proteins. Similar reporters have been used to assess IVS3 splicing in vivo (Laski and Rubin 1989; Roche et al. 1995). We synthesized a panel of $~ 500$-base-pair (bp) dsRNAs targeted to the mRNAs encoding the RNA-binding proteins of interest as well as a negative control dsRNA from a bacterial plasmid to perform RNAi knockdown experiments in somatic Drosophila Schneider line-2 (S2) tissue culture cells. We focused our efforts on the predicted and known RNAbinding proteins, excluding the U1 snRNP components (the loss of which could inhibit splicing) as well as translation factors and nucleases, which are common contaminants in the nuclear extract preparations. The S2 cells were incubated with different dsRNAs individually and then also transfected with a splicing reporter construct containing the P-element exon 3-IVS3-exon 4 sequences (Laski and Rubin 1989). Splicing of IVS3 was assayed by RT-PCR. Immunoblotting with specific antibodies, when available, was used to confirm the effective knockdown of the target proteins upon RNAi (Fig. 2C).

Consistent with the previous findings in hrp48 mutant flies (Hammond et al. 1997), knockdown of hrp48 by RNAi in Drosophila somatic tissue culture cells resulted in activation of IVS3 splicing from this reporter (Fig. 2A,B, lane 16), defined in this RT-PCR assay by an increase in the intensity of the bands corresponding to the spliced P-element mRNA relative to the band corresponding to the unspliced (intron-retained) form of the P-element mRNA. Sequencing analysis of the RT-PCR cDNA products revealed that the predominant spliced product was one that included a cryptic exon cassette between exon 3 and exon 4 rather than direct jointing of exon 3 and exon 4 (data not shown). This product was also detected in previous studies (Chain et al. 1991; Hammond et al. 1997). It is not known whether this product is normally expressed naturally in the fly germline, but, in any case, this does not affect the conclusion that hrp48 knockdown activates splicing from the "accurate" IVS3 5' splice site. However, unexpectedly, RNAi knockdown of PSI did 
A

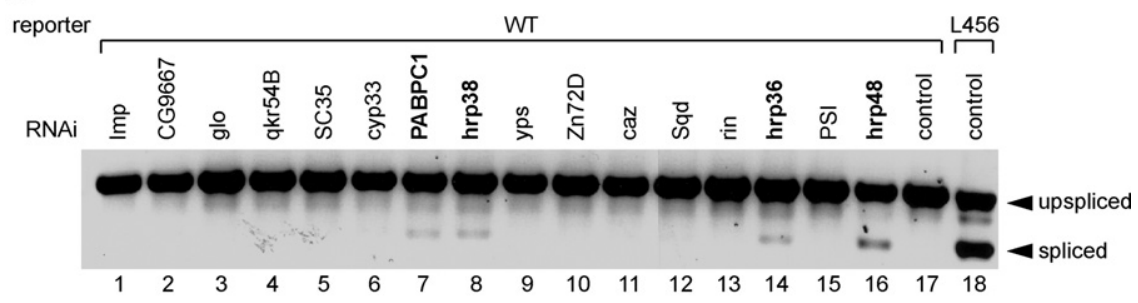

B

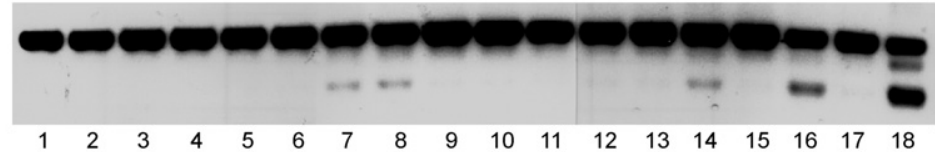

C

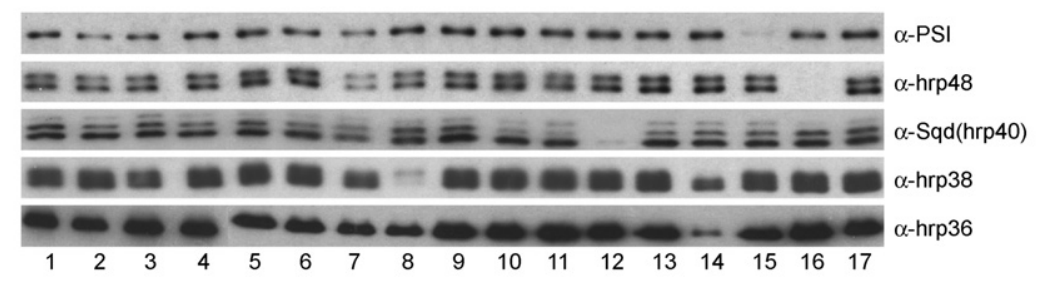

D

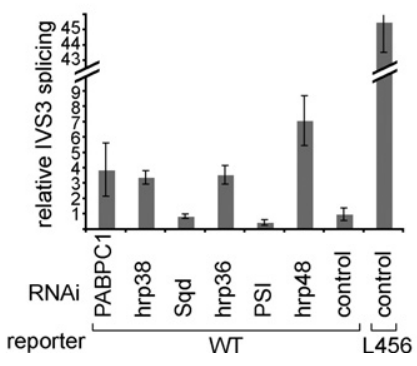

E

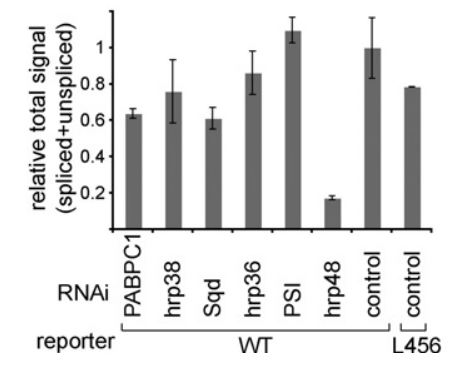

Figure 2. The effects of RNAi of the identified proteins on P-element IVS3 splicing repression. (A) The SL2 cells were subjected to RNAi for the individual proteins indicated above and transfected with the P-element exon 3-IVS3-exon 4 reporter construct, and splicing efficiency of the reporter was assayed by RT-PCR with the primers located within exon 3 and exon 4. Fourteen more proteins not shown here were subjected to RNAi in the same assay, and none of them resulted in IVS3 splicing activation (data not shown; see Supplemental Table 1 for the complete list of the proteins tested). (B) Reproducibility of the RNAi effects on IVS3 splicing repression. This shows the data from an independent RNAi and RT-PCR experiment performed in the same way as in $A$ but on a different date. (C) Immunoblot showing efficient knockdown of the target proteins upon RNAi. Equal volumes of the cell suspensions from the experiment in $A$ were subjected to SDS-PAGE and Western transfer and were probed with the antibodies indicated at the right. Note the cross-reactivity between hrp38 and hrp36 (Blanchette et al. 2009). (D) The relative levels of the IVS3 splicing activation quantified by PCR with $\alpha-{ }^{32} \mathrm{P}$-dCTP and reduced cycle number. Each RNAi was tested at least twice, and the error bars represent standard deviations. (E) Quantification of the total (unspliced + spliced) signal intensities of the RT-PCR products relative to the control RNAi samples. Equal amounts of the reverse-transcribed cDNA samples were subjected to PCR at the same time and electrophoresed in the same gel to ensure that the input radioactivity and the exposure condition were equal between the samples.

not detectably activate IVS3 splicing in this assay (Fig. 2A, $\mathrm{B}$, lane 15). Quantitative PCR with reduced cycle numbers suggested that RNAi of PSI might even have an inhibitory effect, if anything, on the IVS3 splicing in this assay (Fig. $2 \mathrm{D}, \mathrm{E})$. The result observed with this IVS3 splicing reporter in S2 cells is inconsistent with the previous studies in which reduction of the PSI protein (addition of anti-PSI antibodies to in vitro splicing reactions and antisense ribozyme targeting of PSI mRNA in the fly embryos) consistently caused activation of IVS3 splicing (Siebel et al. 1994, 1995; Adams et al. 1997). Both our immunoblotting and biochemical purification data (Siebel et al. 1995; data not shown) and analysis of PSI RNA sequencing (RNAseq) data from the publically available modENCODE project indicate that the levels of PSI mRNA and protein in both the Kc and S2 cells lines are significantly lower compared with previously assayed animal tissues (embryos, fly heads, or ovaries) and could explain the lack of splicing activation upon PSI RNAi knockdown in S2 cells with this splicing reporter assay. Moreover, based on the modENCODE RNA-seq data, the levels of hrp48, hrp36, and hrp38 are about fivefold to 10-fold higher than PSI mRNA. Finally, in the female germline, where IVS3 splicing occurs at a low level (Roche et al. 1995), there is no PSI expression (Siebel et al. 1995), but there is high hrp48, hrp36, and hrp38 expression. Thus, while PSI expression in many somatic tissues may be the final block to any IVS3 splicing, the presence of the hrp proteins may dominate to give repression in some cell types with low PSI levels. Despite the difference in PSI levels in S2 cells compared with animal tissues, the RT-PCR assay is capable of reporting the robust activation of IVS3 splicing in S2 cells upon hrp48 knockdown and with the L456 splicing silencer mutations and thus is useful for identifying the functional role of the putative new components of the splicing silencer complex identified by mass spectrometry.

Among the 30 proteins/mRNAs from the mass spectrometry experiments that were tested, RNAi depletion of three proteins/mRNAs [hrp36, hrp38, and PABPC1, the predominantly cytoplasmic form of poly(A)-binding protein, also known as pAbp] in addition to hrp48 resulted in an activation of IVS3 splicing (Fig. 2A,B, lanes 7,8,14). RNAi of each of these three proteins resulted in a threefold to fourfold increase of IVS3 splicing relative to the control RNAi samples. These were more modest effects compared with hrp48 RNAi treatment, which caused a sevenfold activation of IVS3 splicing (Fig. 2D,E). hrp36 
and hrp38, like hrp48, are Drosophila homologs of the vertebrate hnRNP A/B proteins (Haynes et al. 1991; Matunis et al. 1992a). Characterization of the four Drosophila hrp protein family members indicated distinct sequence highaffinity RNA-binding sites, but enrichment of these motifs was observed in genome-wide analysis of splicing targets controlled by these proteins (Blanchette et al. 2009). The effect of hrp36 and hrp38 knockdown on IVS3 splicing was specific because RNAi of other hnRNP homologs tested (Sqd [hrp40], Rb97D, glo, and CG17838) did not cause the same effect. Immunoblotting of the affinitypurified RNP complexes showed enrichment of hrp36 on the wild-type RNA relative to the L456 RNA, consistent with a role for hrp36 and hrp38 in P-element silencer function and the effects of depleting hrp36 and hrp38 on activation of IVS3 splicing (Fig. 1D). While the hrp38 protein was readily detectable on the L456 RNA, it was still more highly enriched on the wild-type RNA (Fig. 1D). Taken together, these results indicate that hrp36, hrp38, and PABPC1 function at the P-element ESS to block IVS3 splicing in somatic cells.

To understand how these factors might collaborate in the context of the IVS3 splicing silencer, we knocked down two mRNAs/proteins simultaneously and looked for synergistic effects on IVS3 splicing activation (Fig. 3). The total amount of dsRNA used per cell is the same as in the original experiment (Fig. 2). However, the concentration of specific dsRNA is diluted in half with control dsRNA to compensate for the dual knockdown samples. This dilution of dsRNA caused a slight decrease in the effects of relative IVS3 splicing compared with the experiments in Figure 2. The double RNAi of hrp $48+h r p 36$ or hrp $48+$ hrp38 achieved a synergistic activation of IVS3 splicing to a much greater extent than RNAi of each mRNA alone. However, in other cases, the effects of double RNAi knockdown was additive (e.g., PABPC1+ hrp38). Double RNAi of hrp36+hrp38 caused a modest but reproducible increase of IVS3 splicing compared with the hrp36 + control or hrp38 + control RNAi. These observations are consistent with the idea that hrp48 acts

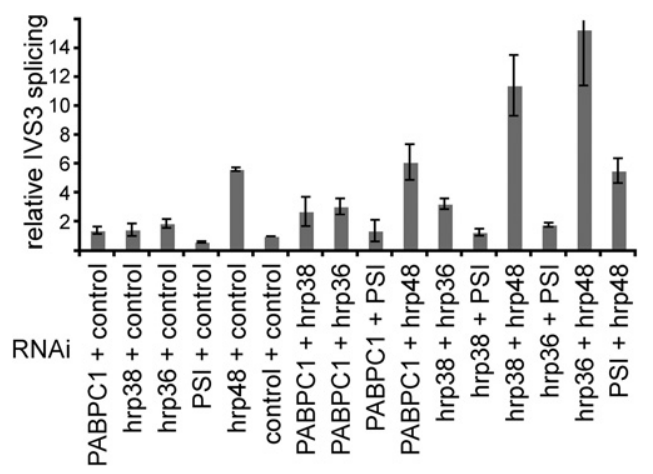

Figure 3. The effects of double RNAi on P-element IVS3 splicing repression. Two dsRNA preparations were mixed and applied simultaneously to the cells and assayed with the same method as in Figure 2D. Samples with a single dsRNA were diluted in half with control dsRNA to keep the total dsRNA concentration consistent throughout all samples. in conjunction with hrp36 and hrp38 to cause splicing repression. The effect of PABPC1 RNAi combined with another RNAi was more variable. Taken together, these results indicate that hrp36 and hrp38 can cooperate with hrp48 to mediate splicing repression at the P-element ESS.

Interaction of purified recombinant P-element silencer proteins with silencer $R N A$-influence of hrp48 on hrp36 and hrp38 binding

Previous SELEX and RNA-binding experiments identified the preferred RNA-binding motifs for hrp48, hrp36, hrp38, and PSI (Amarasinghe et al. 2001; Blanchette et al. 2009). While the P-element IVS3 5' ESS RNA contains sequences that match SELEX motifs for hrp48, PSI, and PABPC1, there are no high-affinity binding motifs for the hrp38 and hrp36 proteins. To test whether hrp36 and hrp38 can bind to the P-element RNA despite the lack of SELEX motifs, we performed RNA-binding experiments using purified recombinant proteins. hrp48 was expressed in baculovirus-infected insect cells as an MBP-TEV fusion protein to aid protein solubility. All other proteins were His6-tagged proteins expressed and purified from Escherichia coli. RNA electrophoretic mobility shift assays (EMSAs) with the same 69-nt (wild-type) P-element silencer RNA sequence showed that several proteins, including hrp48, PSI, and PABPC1, bind the P-element silencer RNA with high affinity (Fig. 4D [5-50 nM], A [PABPC1, lanes 1-6; PSI, lanes 7-12; MBP-hrp48, lanes 13-20], C [hrp48, lanes 1-12]). These proteins have recognizable SELEX or high-affinity motifs that are found within the silencer RNA. Note that the MBP-hrp48 fusion protein binds RNA with lower affinity than the TEVcleaved hrp48 protein lacking the MBP tag (Fig. 4, cf. A [lanes 13-20] and C [lanes 1-12]). In contrast, the hrp38 and hrp36 proteins bind the P-element RNA with very low affinity (Fig. 4D [micromolar per kilodalton], B [hrp38, lanes 1-16; hrp36, lanes 8-13]). The lack of SELEX motifs for hrp36 and hrp38 proteins on the P-element silencer RNA provides an explanation for the observed low-affinity RNA binding of these two proteins. However, this observation raises the question of how these two functionally important RNA-binding proteins, hrp36 and hrp38, specifically bind a complex formed on the P-element IVS3 5' exon silencer RNA (Fig. 1D) despite having no high-affinity binding sites on that RNA (Fig. 4D). It should be pointed out that the intracellular concentrations of hrp48, hrp36, and hrp38 are approximately the same, based on purification (Matunis et al. 1992a,b), modENCODE RNA-seq data, and our own immunoblotting experiments (Blanchette et al. 2009).

Since hrp36 and hrp38 do not appear to associate with the P-element splicing silencer complex by specifically binding the P-element RNA, we hypothesized that other interacting factors might facilitate their recruitment or stabilize their binding to the silencer RNA element. The synergistic effect of hrp48 with hrp38 and hrp36 in the minigene reporter splicing assay (Fig. 3) suggests that hrp48, which has a high-affinity binding site on the P-element exonic silencer RNA (Fig. 4D; Siebel et al. 


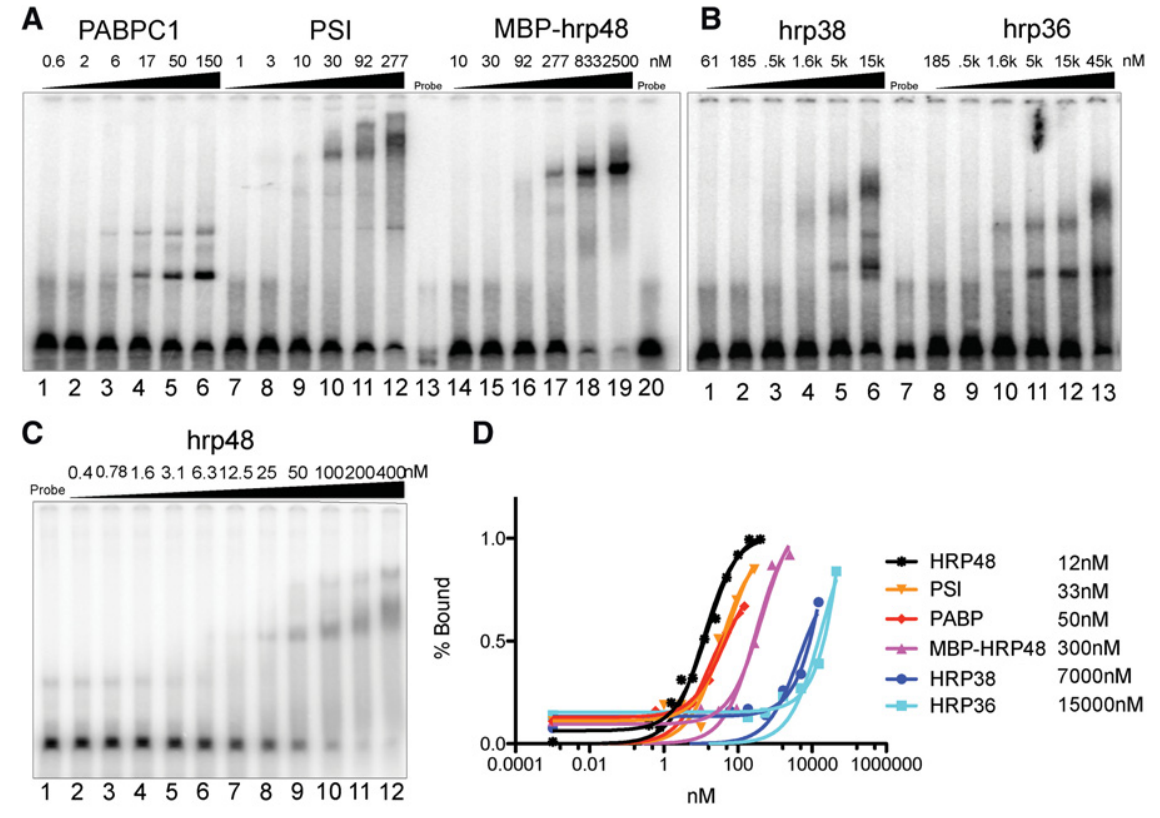

Figure 4. RNA binding of wild-type P-element silencer RNA using purified recombinant P-element silencer proteins. $(A-C)$ Native gel electrophoresis RNA-binding assays of ${ }^{32}$ P-labeled wild-type P-element silencer RNA with the indicated final concentrations of purified recombinant proteins. Bound and free RNAs are indicated. (D) Quantification of the percent RNA bound per total input RNA in each lane as a function of the indicated protein concentration. Apparent dissociation constants $\left(K_{\mathrm{d}}\right)$ were determined by fitting data to a single-site binding curve.
1994), might interact with hrp38 and hrp36 to stabilize their RNA binding during splicing silencing of P-element IVS3. Indeed, evidence for an interaction of this type was observed in vitro when a low concentration of hrp48 protein $(20 \mathrm{nM})$ was combined with the other P-element silencer proteins in RNA gel mobility shift assays (Fig. 5). The RNA-protein complexes observed with high concentrations of hrp36 and hrp38 were supershifted upon addition of substoichiometric amounts of hrp48 protein (Fig. 5, lanes 3,4 [arrowheads], 7,8), while the addition of hrp48 caused no appreciable change of the RNA-protein complexes formed with PSI and PABPC1 (Fig. 5, lanes $11,12,15,16)$. However, under both gel shift and RNA pull-down assay conditions (see the next section, below) with subsaturating amounts of hrp48 and increasing amounts of hrp36 and hrp38, hrp36 and hrp38 do not appear to increase the binding of hrp48 (Supplemental Fig. $3)$. Interpreting how hrp48 interacts with hrp38 and hrp36 on the RNA using a gel shift assay is complicated by the fact that migration of protein-RNA complexes on native gels does not always correlate with molecular weight. It seems likely that the hrp48-induced supershift is a result of hrp48 binding the same RNA as hrp38 or hrp36. The relative concentration of the two proteins in the reactions and the subsequent intensity and migration of the gel shift complexes for the hrp48, hrp36, and hrp38 proteins alone (Fig. 5, lanes 2,3,7), compared with the intensity and migration of the complexes when the proteins are combined with hrp48 (Fig. 5, lanes 4,8), suggest that, in addition to binding the RNA, hrp48 might also induce changes in the stability or conformation of the interaction between hrp38 or hrp36 and the P-element silencer RNA. Regardless of the exact RNP complex configuration, hrp36 and hrp38 interact with hrp48 and the P-element silencer RNA to create distinct RNA-protein complexes that are not observed when the three hrp proteins separately bind the RNA on their own. These data suggest that high-affinity binding by hrp48 might influence or stabilize the binding of hrp36 and hrp38 to low-affinity RNA sites on the P-element RNA. A similar type of observation was made previously for mammalian hnRNPA1 protein binding to RNAs that had a mixture of high-and low-affinity RNA-binding sites (Zhu et al. 2001).

\section{hrp48 and RNA can recruit hrp36 and hrp38 to the P-element silencer RNA}

The synergistic effects of depleting hrp36 or hrp38 along with hrp 48 on abrogating splicing silencing in the dual RNAi knockdown experiments and the supershift native gel complexes formed in vitro on the silencer RNA in the gel shift assays indicate that hrp36 and hrp38 can functionally and biochemically interact with hrp48. However,

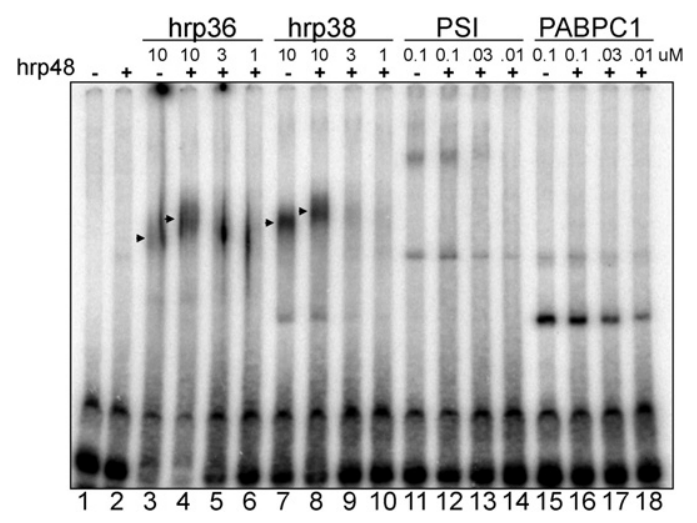

Figure 5. RNA supershifts on native gels of hrp36 and hrp38 by addition of hrp48. Native gel electrophoresis RNA-binding assays of ${ }^{32}$ P-labeled wild-type P-element silencer RNA, as in Figure 4. A low concentration of hrp48 protein $(20 \mathrm{nM})$ was added in the indicated lanes. The supershifted hrp48-containing complexes are indicated by arrowheads. 
these data do not directly provide any understanding about how the two newly identified hrp36 and hrp38 proteins are recruited to the P-element splicing silencer complex. To directly test whether hrp48 RNA binding to the silencer RNA is capable of recruiting hrp38 and hrp36 to the RNA, we synthesized the same 69-nt wild-type silencer RNA with biotin UTP substitution for use in an RNA pull-down assay. Biotinylated RNA was prebound to NeutrAvidin resin, incubated with a low concentration of the hrp36 and hrp38 proteins (200 nM each), and combined with increasing concentrations of hrp48 protein (Fig. 6A, lanes 8-12). As increasing amounts of hrp48 protein bound to the P-element silencer RNA, increasing amounts of hrp36 and hrp38 proteins were retrieved with the silencer RNA. These experiments implicate hrp48 as the critical link to explain how the functionally
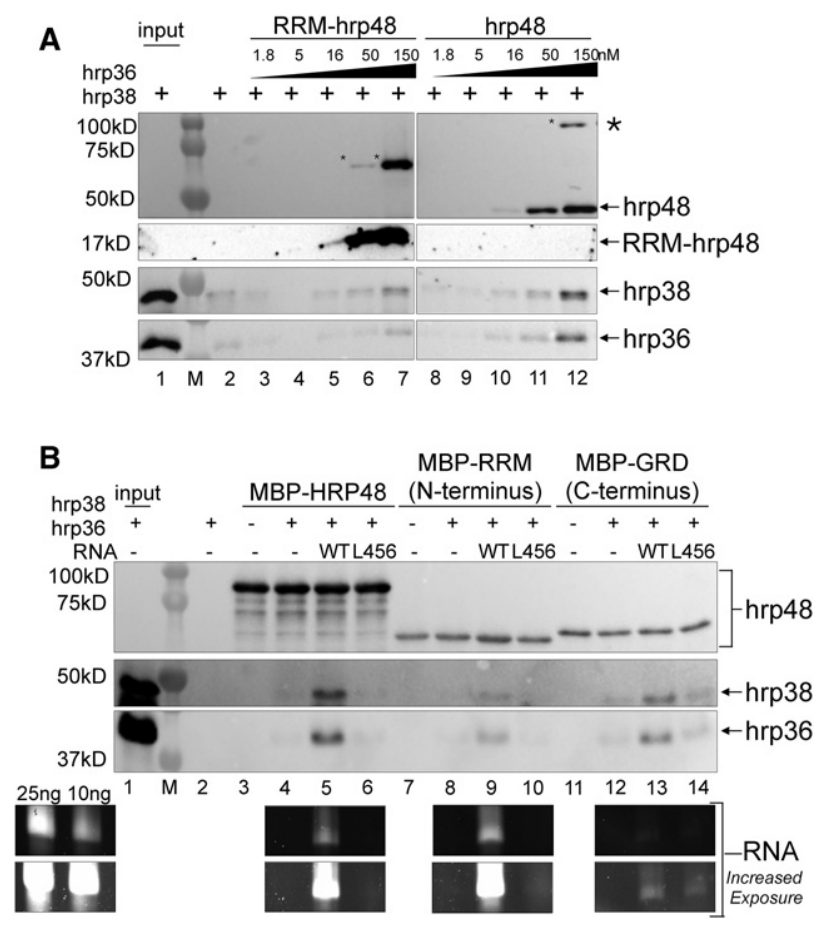

Figure 6. Immobilized RNA and MBP-hrp48 protein pull-downs of hrp36 and hrp38. (A) P-element silencer RNA pull-down. Biotinylated wild-type P-element RNA prebound to $50 \mu \mathrm{g} / \mathrm{mL}$ NeutrAvidin resin was incubated with hrp36 and hrp38 (200 nM each) and hrp48 or the RRM domain of hrp48 at the indicated concentrations. Immunoblots of proteins retrieved from washed RNA resins were probed with specific antibodies against the proteins indicated at the right. Asterisks indicate residual uncleaved MBP-hrp48 or MBP-RRM fusion proteins bound to the RNA. (B) MBP-hrp48 protein pull-down. Full-length hrp48 (MBP-HRP48), the RRM domain of hrp48 (MBP-RRM), or the GRD of hrp48 (MBP-GRD) fusion proteins, bound to amylose resin and with wild-type P-element silencer RNA, L456 mutant silencer RNA, or no RNA were incubated with $200 \mathrm{nM}$ hrp36 or hrp38. Immunoblots of proteins retrieved from washed hrp48 resins were probed with specific antibodies against the proteins indicated at the right. (Bottom) RNAs bound to and purified from hrp48 immobilized protein resins were visualized on $10 \%$ acrylamide with SYBR Gold fluorescent stain. important hrp38 and hrp36 proteins are recruited to the P-element splicing silencer complex despite their lack of high-affinity binding sites on the silencer RNA. Our initial idea was that the hrp36 and hrp38 proteins are tethered to the P-element silencer RNP through protein-protein interactions with the glycine-arginine-rich (GRD) domain of hrp48, while the RRM domain of hrp48 bound to its high-affinity binding site on the P-element RNA. However, we were surprised to find that protein-protein interactions between the proteins required the presence of the P-element silencer RNA in an MBP-hrp48 fusion protein pull-down assay (Fig. 6B, lanes 2-6).

All four of the Drosophila hrp family proteins share the same general structure as the human hnRNPA1 protein. They can be divided into an $\mathrm{N}$-terminal half that contains two RRM-type RNA-binding domains and a C-terminal half that contains a low-complexity (LC) GRD. The ability of hnRNPA1 to cooperatively bind and spread along an exon RNA is associated with splicing silencing (Mayeda et al. 1994), and the C-terminal GRD of hnRNPA1 is responsible for the cooperative RNA-binding properties of the protein (Zhu et al. 2001; Okunola and Krainer 2009). We wanted to know whether either the RRM domain or GRD of hrp48 might be directly responsible for recruitment of hrp36 and hrp38 to the P-element RNA. To test this idea, we divided hrp48 into two halves and purified MBP-TEV-RRM and MBP-TEV-GRD fusion proteins from baculovirus-infected insect cells. In the RNA pulldown assay, the GRD of hrp48 did not bind RNA with high enough affinity to be retrieved (data not shown). The hrp48-RRM domain binds the P-element silencer RNA, and increasing amounts of the hrp48-RRM protein resulted in retrieval of both the hrp36 and hrp38 proteins (Fig. 6A, lanes 3-7). This result differs from human hnRNPA1 and shows that, in the case of the P-element silencer RNA, the ability of hrp48 to recruit low-affinity or sequence-nonspecific RNA-binding proteins to the RNA is not solely dependent on the GRD of the protein. This observation fits with the results from the full-length hrp48 pull-down experiment (Fig. 6B, lanes 2-6), which showed that the recruitment of hrp36 and hrp38 by hrp48 is not simply through a protein-protein interaction but requires the presence of the RNA. Protein pull-downs with the full-length hrp48 protein or the RRM and GRD halves show that the presence of the wild-type P-element silencer RNA causes a significant increase in hrp36 and hrp38 RNA binding (Fig. 6B, lanes 5,9,13) compared with the "no RNA added" control (Fig. 6B. lanes 4,8,12) or the L456 mutant RNA (Fig. 6B, lanes 6,10,14). The two RRM-type RNA-binding domains of hrp48 confer the high-affinity sequence-specific RNA binding of hrp48 to the wild-type P-element RNA, and thus the lack of the mutant L456 RNA binding to the full-length hrp48 and the hrp48-RRMs in the RNA pull-downs was expected (Fig. 6B, lanes 6,10). The GRD can weakly bind RNA nonspecifically (possibly due to the arginine residues) and offers an explanation for the reduced levels of RNA bound (Fig. 6B, lanes 13,14). However, the increase in hrp36 and hrp38 protein retrieval with the hrp48GRD in the presence of the wild-type RNA and the slight 
enrichment of wild-type RNA compared with the L456 RNA (Fig. 6B, lanes 13,14) is not so easily explained. Within the GRDs of many RNA-binding proteins, there are LC regions that allow the proteins to form higher-order $\beta$-sheet fibers (Kato et al. 2012; Kwon et al. 2013). In this regard, RNA was shown to be able to seed higher-order fiber formation with the RNA-binding protein FUS (Schwartz et al. 2013). hrp36, hrp38, and hrp48 all have LC regions that make them susceptible to higher-order $\beta$-sheet fiber formation. At high concentrations, hrp36 was observed to form a hydrogel (Kato et al. 2012; data not shown). It seems likely that the LC regions of all three Drosophila hrp proteins contribute to the GRD pull-down results (Fig. 6B, lanes 12,13,14). Thus, the stabilization of hrp36 and hrp38 on the P-element silencer RNA by hrp48 may involve both protein-protein and RNA-protein interactions.

\section{Discussion}

The P-element ESS was among the first alternative splicing regulatory elements to be identified. Our laboratory identified the RNA-binding proteins PSI, hrp48, and spliceosomal U1 snRNP as some of the core components of the P-element somatic splicing silencer complex (Siebel et al. 1992, 1994). In this study, taking a more systematic approach now available using mass spectrometry and RNAi, we identified additional proteins that can assemble on the IVS $35^{\prime}$ exon RNA in vitro and obtained evidence indicating that three of them are functional components of this alternative splicing regulatory mechanism. Our results implicate two additional Drosophila hnRNP A/B protein homologs (hrp36 and hrp38) in addition to hrp48 in the somatic splicing repression of the P-element IVS3. Previous UV cross-linking experiments showed that two $\sim 40-\mathrm{kDa}$ proteins were cross-linked preferentially to the wild-type 5' exon RNA (Siebel and Rio 1990; Chain et al. 1991), and thus, based on their size, it is highly likely that their identities were hrp36 and hrp38. This further supports a model in which hrp36, hrp38, and hrp48 mediate IVS3 splicing repression by directly interacting with the 5' exon RNA (Supplemental Fig. 4). However, given the fact that the hnRNP A1 protein can mediate protein-protein interactions through its glycine-rich domain (Blanchette and Chabot 1999) and that hrp36 and hrp38 can bind various RNAs relatively nonspecifically (Siebel and Rio 1990), it is also possible that their assembly on the IVS3 $5^{\prime}$ exon RNA is stabilized by the presence of hrp48. In fact, RNA pull-down and RNA-protein-binding experiments in which hrp48 is bound to the P-element $5^{\prime}$ exon indicate that hrp36 and hrp38 are recruited to the P-element silencer RNA via protein-protein interactions with hrp48 and that both hrp36 and hrp38 bind the P-element RNA with extremely low affinity. This observation is consistent with the lack of high-affinity hrp36 and hrp38 RNA-binding sites (Blanchette et al. 2009) on the P-element 5' exon silencer element. The synergistic effects seen with the double RNAi of hrp36 or hrp38 and hrp48 also suggest that they contribute to splicing silencing, probably in physical proximity to each other. Interest- ingly, LC sequence domains on human counterparts of hrp36 and hrp38 as well as the RNA-binding protein FUS and the C-terminal repeat domain of RNA polymerase can interact to form polymeric associations triggered by RNA (Han et al. 2012; Kato et al. 2012; Kwon et al. 2013; Schwartz et al. 2013). It is possible that the recruitment of hrp36 and hrp38 to the P-element RNA by hrp48 may also be related to the behavior of these LC domains.

Recent genome-wide studies have shown that many splice junctions in Drosophila and humans are coregulated by more than one member of the hnRNP A/B family of proteins (Blanchette et al. 2009; Huelga et al. 2012). Moreover, RNA immunoprecipitation (RIP)-chip assays for hrp36, hrp38, hrp40, and hrp48 indicated that, at many locations in the Drosophila genome, two or more hrp proteins are bound to transcript regions regardless of whether a high-affinity SELEX motif for each protein was present in the vicinity, suggesting that, on cellular transcripts, different hrp family members might be recruited to weak binding sites by interaction with other hrp proteins binding to high-affinity sites (Blanchette et al. 2009). Similar ideas have been put forward for the cooperative binding of mammalian hnRNPA1 to splicing silencers (Zhu et al. 2001; Okunola and Krainer 2009). It is possible that there are distinct combinations and configurations of the hrp proteins that are commonly used in the transcriptome and that the P element might have co-opted one of these prevalent mechanisms during evolution.

Involvement of PABPC1 in the IVS3 splicing repression is intriguing. We can postulate at least a few different models, which are not mutually exclusive, to account for our results. First, the well-known functions of PABPC1 are a general role in positively regulating the translation efficiency and stability of mRNAs (Mangus et al. 2003). However, it is also known in mammals that PABPC1 can shuttle into and out of the nucleus and can bind to nuclear pre-mRNA (Afonina et al. 1998; Hosoda et al. 2006; Lemay et al. 2010), so it seems plausible that PABPC1 could play a role in P-element splicing silencer function. Indeed, using purified recombinant PABPC1, we showed that there is a high-affinity binding site-most probably an AU-rich element (AAGAAAATATATAATAG)between the P-element splicing silencer and the accurate IVS3 $5^{\prime}$ splice site. Thus, PABPC1 may mediate the IVS3 splicing repression through its physical association with the 5' exon sequence, much like the hrp proteins. Interestingly, again, previous UV cross-linking studies of somatic proteins to the P-element $5^{\prime}$ exon RNA identified an $\sim 65-\mathrm{kDa}$ protein, which is similar to the molecular weight of PABPC1 (Siebel and Rio 1990; Siebel et al. 1992). Although PABPC1 is generally known as a protein that binds the $3^{\prime}$ poly(A) tails of mRNA, the notion that it may also bind internal sequences is not unprecedented (de Melo Neto et al. 1995; Afonina et al. 1998; Gilbert et al. 2007). Second, the effect of PABPC1 on IVS3 splicing may be due to the unique biological requirements of the IVS3 alternative splicing intron retention event with respect to nuclear export and nonsense-mediated mRNA decay (NMD), two other processes in mRNA biogenesis that are themselves functionally coupled (Reed and Hurt 
2002). It is known that the unspliced, IVS3-retained RNA is efficiently exported to the cytoplasm and encodes a truncated transposition repressor protein (Misra and Rio 1990). As noted above, PABPC1 is predominantly cytoplasmic but can shuttle between the nucleus and cytoplasm (Afonina et al. 1998; Lemay et al. 2010) and binds to nuclear RNAs (Hosoda et al. 2006). Its function in nuclear mRNA export has been suggested in other organisms (Afonina et al. 1998; Brune et al. 2005; Dunn et al. 2005). Moreover, Izaurralde and colleagues (BehmAnsmant et al. 2007) have found that PABPC1 has a role in mRNA surveillance via NMD and that artificially tethering PABPC1 to an internal sequence allows premature stop codon-containing mRNAs to evade NMD. These features of PABPC1 fit nicely with the special needs of P-element IVS3 alternative splicing; namely, nuclear export of a message while retaining the intron and evasion of NMD while carrying an early internal translation termination codon in IVS3. It is tempting to speculate that the nuclear export and/or NMD-related machineries function in conjunction with the splicing silencer complex and that the loss of the splicing components also disrupts the downstream steps and possibly vice versa.

The P-element IVS3 ESS uses the sequence-specific RNA-binding proteins hrp48 and PSI to interact with the silencer element RNA (Siebel et al. 1994, 1995). Using biochemical assembly and purification, we identified additional components that are recruited to the P-element silencer RNA; namely, hrp36 and hrp38. These results have important implications for splicing regulation, since these proteins, while functioning in splicing repression, do not have high-affinity RNA-binding sites on the P-element RNA (Supplemental Fig. 4). It is sometimes the case that proteins that are part of a RNP complex do not bind their RNA targets solely through sequence-specific RNA-protein contacts. This idea predicts that hrp36 and hrp38 might be bound to sites in the Drosophila transcriptome that do not have high-affinity RNA-binding motifs. In fact, this is exactly what we observed in RIP tiling microarray experiments examining the distribution of the four Drosophila hrp proteins on nuclear pre-mRNA (Blanchette et al. 2009). Thus, while RNA-protein interactions such as those found by individual nucleotideresolution cross-linking immunoprecipitation (iCLIP) or high-throughput sequencing combined with CLIP (HTSCLIP) may be important for splicing regulation, it is also possible that there are additional proteins that control alternative splicing as part of a larger RNP but do not bind the RNA regulatory elements with high affinity or specificity. This observation will complicate the analysis of mechanisms of alternative splicing regulation and how they evolve.

\section{Materials and methods}

\section{DNA plasmid constructs and antibodies}

The template for the RNA used in the purification experiments was the P-element DNA fragment that started at the PstI site at position 1911 in the 5' exon (O'Hare and Rubin 1983) and includ- ed the entire IVS3, which was subcloned into the pGEM2 vector. The L456 mutant sequence was the combination of mutations \#4, \#5, and \#6, described previously (Chain et al. 1991). For the in vitro purification of splicing silencer complexes, the accurate IVS3 5 ' splice site was mutated so that it would not be capable of binding U1 snRNP (Siebel et al. 1992). The splicing reporter construct was generated by PCR-amplifying the entire exon 3-IVS3-exon 4 sequences with the addition of a start codon at the beginning of exon 3 and subcloning the amplified fragment into pMT/V5-His vector (Invitrogen). This reporter carries the same P-element IVS3 and flanking exon sequences that we used previously and contains a wild-type IVS3 5' splice site (Roche et al. 1995; Adams et al. 1997). The cDNA clones used for making the dsRNA templates were obtained from the Drosophila Genomics Resource Center. The polyclonal antibodies against PSI and hrps were as described previously (Siebel et al. 1995; Blanchette et al. 2009). hrp36, hrp38, PSI, and PABPC1 are His6 fusions expressed in and purified from $E$. coli.

Recombinant plasmids for bacterial expression of hrp48, hrp36, and hrp38 were as described previously (Blanchette et al. 2009). The His6-MBP-TEVhrp48 and N-terminal (M1-P173) and C-terminal (P221-V421) halves were cloned into pVL1393, and baculoviruses were generated using Expression Systems BestBac 2.0 vector in Sf9 cells.

Purification of the P-element RNP complexes and mass spectrometry

The splicing-competent nuclear extracts were prepared using the somatic Kc cell culture as described (Dignam et al. 1983; Rio 1988). These cells grew without serum and in suspension culture. The levels of PSI in this cell line were low relative to most somatic tissues and developmental stages in the organism (modENCODE RNA-seq data). The P-element plasmid template was linearized with DraI, which cuts at position 13 of IVS3, and was used for the standard in vitro transcription reaction with T7 RNA polymerase, which also contained $\alpha-{ }^{32}$ P-UTP and biotin-16-UTP (Roche) in addition to ordinary UTP. The UTP to biotin-16-UTP ratio was adjusted to $12.5: 1$ so the synthesized RNAs had, on average, one to two biotins per molecule. The synthesized RNA was purified with the RNeasy kit (Qiagen).

The RNP complex was assembled for $30 \mathrm{~min}$ at room temperature in a reaction mixture containing $20 \mathrm{mM} \mathrm{HEPES-KOH}(\mathrm{pH}$ 7.6), $5 \mathrm{mM} \mathrm{MgCl}_{2}, 40 \mathrm{mM} \mathrm{KCl}$ (in addition to the $\mathrm{KCl}$ in the nuclear extract, dialyzed against $100 \mathrm{mM} \mathrm{KCl}$ ), $0.5 \mathrm{U} / \mu \mathrm{L}$ RNasin (Promega), $250 \mathrm{nM}$ RNA, and 30\% nuclear extract in 2-4 mL. Omission of $\mathrm{MgCl}_{2}$ or $\mathrm{KCl}$ did not seem to affect the results significantly. The reaction was then loaded onto a 100-cm Sephacryl S-500 gel filtration column containing FSP buffer $(20 \mathrm{mM}$ Tris$\mathrm{HCl}$ at $\mathrm{pH} 7.6,60 \mathrm{mM} \mathrm{KCl}, 2.5 \mathrm{mM}$ EDTA, $0.1 \%$ Triton $\mathrm{X}$-100). In separate experiments, $0.8 \mathrm{~mL}$ of the same reaction mixture was loaded on a $10-\mathrm{mL} 8 \%-25 \%$ glycerol gradient in FSP buffer and centrifuged in a Beckman SW41 rotor at 24,000 rpm for $16 \mathrm{~h}$, and $0.5-\mathrm{mL}$ fractions were manually collected. The peak fractions from the gel filtration were pooled and incubated with $200 \mu \mathrm{L}$ of NeutrAvidin agarose beads (Pierce) previously equilibrated with FSP for $3 \mathrm{~h}$ in the cold room. The beads were washed four times with $60 \mathrm{mM} \mathrm{NaCl}$ and $20 \mathrm{mM}$ Tris- $\mathrm{HCl}(\mathrm{pH}$ 7.6). The bound proteins were eluted with $200 \mu \mathrm{L}$ of $8 \mathrm{M}$ urea and $100 \mathrm{mM}$ Tris- $\mathrm{HCl}(\mathrm{pH} 7.6)$ and then with $200 \mu \mathrm{L}$ of $5 \%$ formic acid. The formic acid eluate was vacuum-dried and resuspended in the urea eluate. One molar tris base solution was added to the combined eluate to obtain neutral $\mathrm{pH}$. The eluate was then diluted fourfold with water and incubated with $0.5 \mu \mathrm{L}$ of RNaseA (Fermentas) for $30 \mathrm{~min}$ at $37^{\circ} \mathrm{C}$. The proteins were precipitated 
with the addition of trichloroacetic acid to $20 \%$ and centrifugation. The protein pellet was washed with acetone four times and finally resuspended in $100 \mu \mathrm{L}$ of $8 \mathrm{M}$ urea and $100 \mathrm{mM}$ Tris- $\mathrm{HCl}$ (pH 7.6).

We also performed a purification experiment using the PP7tagged P-element RNA. A single PP7 hairpin tag (Lim et al. 2001) was fused to the P element at the SphI site at position 1869 (O'Hare and Rubin 1983), which is $\sim 50$ bp $5^{\prime}$ to the F1/F2 sites. In the preliminary experiments, we also tested a few alternative constructs that had the PP7 tag at various positions in the $3^{\prime}$ intron. However, these $3^{\prime}$-tagged RNAs failed to retrieve U1 snRNP, hrp48, or PSI. The his-tagged MBP-PP7 fusion protein was expressed in E. coli and purified with nickel column and heparin column chromatography. Binding and elution were carried out essentially as described for the analogous MS2-MBP purification strategy (Zhou and Reed 2003).

A small fraction of the purified protein sample was resolved in a $10 \%$ SDS-PAGE gel and stained with silver or subjected to immunoblotting. The rest of the sample was trypsinized and subjected to MudPIT analysis (Washburn et al. 2001) at the University of California at Berkeley QB3 Proteomics/Mass Spectrometry Laboratory. Protein identification was done with Integrated Proteomics Pipeline software (IP2, Integrated Proteomics Applications, Inc.) using ProLuCID/Sequest and DTASelect2 (Tabb et al. 2002; Xu et al. 2006; Cociorva et al. 2007; Park et al. 2008). Tandem mass spectra were extracted into ms 1 and $\mathrm{ms} 2 \mathrm{fi}-$ les from raw files using RawExtract 1.9.9 (McDonald et al. 2004) and were searched against the Drosophila protein database plus sequences of common contaminants concatenated to a decoy database in which the sequence for each entry in the original database was reversed (Peng et al. 2003). LTQ data were searched with 3000.0 milli-amu precursor tolerance, and the fragment ions were restricted to a $600.0 \mathrm{ppm}$ tolerance. All searches were parallelized and searched on the VJC proteomics cluster. Search space included all tryptic peptide candidates with no missed cleavage restrictions. Carbamidomethylation $(+57.02146)$ of cysteine was considered a static modification, and oxidation of methionine $(+15.9949)$ was a variable modification. We required one peptide per protein and two tryptic termini for each peptide identification. The ProLuCID search results were assembled and filtered using the DTASelect program (version 2.0) (Tabb et al. 2002; Cociorva et al. 2007) with a general peptide false discovery rate (FDR) of 0.005 and a peptide FDR of 0.001 for inclusion at the protein level. Under such filtering conditions, the global peptide FDR was generally near 0 and $<1 \%$ for all samples. Those proteins that had $<1 \%$ sequence coverage were disregarded. Relative abundance calculations resulting in normalized spectral abundance factor (NSAF) (Paoletti et al. 2006) and exponentially modified protein abundance index (EMPAI) (Ishihama et al. 2005) values were done within the IP2 software and manually normalized between data sets.

\section{RNAi and minigene reporter assays in tissue culture}

The templates for the dsRNA synthesis were generated by PCR from the cDNA clones. The PCR primers were designed by using the SnapDragon program, which is designed to minimize the offtarget effects and is available at the Drosophila RNAi Screening Center Web site (http://www.flyrnai.org). The T7 promoter sequence was added to the $5^{\prime}$ end of each primer. All PCR products, including the control dsRNA template corresponding to the pBluescript linker sequence, were between 300 and $600 \mathrm{bp}$ long. The PCR products were purified with the Qiagen QiaQuick PCR purification kit and were used for dsRNA synthesis with T7 RNA polymerase. After removal of the DNA template with the RNase-free DNase (Promega), the RNA was purified with the RNeasy kit and adjusted to $1 \mathrm{mg} / \mathrm{mL}$ in $10 \mathrm{mM}$ Tris$\mathrm{HCl}(\mathrm{pH} 7.5)$ and $100 \mathrm{mM} \mathrm{NaCl}$. The RNA strands were annealed in a heat block by heating to $95^{\circ} \mathrm{C}$ and then cooling down to room temperature. Note that SL2 cells were used for the RNAi experiments because our Kc cells did not show efficient knockdown in our hands. A half-milliliter of cells (at $3 \times 10^{6}$ cells per milliliter) in serum-free M3 medium was incubated with $5 \mu \mathrm{g}$ of dsRNA in 24-well plates. After $1 \mathrm{~h}, 0.5 \mathrm{~mL}$ of the same medium with $10 \%$ fetal bovine serum (FBS) was added. On the second day, the cells were transfected with $200 \mathrm{ng}$ of splicing reporter construct plasmid DNA using the Effectene reagent (Qiagen). On the third day, expression of the reporter RNA was induced by addition of $\mathrm{CuSO}_{4}$ to $0.5 \mu \mathrm{M}$. On the fourth day, the cells were harvested. Ten percent of the cell suspension was saved for immunoblotting, and the remainder of the cells were used for the preparation of total RNA using the Qiagen RNeasy kit. The RNA was treated with the RNase-free DNase (RQ1, Promega), extracted with phenol/chloroform, ethanol-precipitated, washed in ethanol solutions, and finally resuspended in $20 \mu \mathrm{L}$ of water. Two micrograms of total RNA was used in a $20-\mu \mathrm{L}$ reverse transcription reaction containing $200 \mathrm{U}$ of SuperScript II reverse transcriptase (Invitrogen) and $50 \mathrm{ng}$ of random hexamers (Roche). The RT-PCR primer sequences were described previously (Roche et al. 1995). The negative controls with no reverse transcriptase confirmed that DNA contamination in the RNA samples was negligible. The combination of 35-cycle PCR, agarose gel electrophoresis, and ethidium bromide staining was used in the initial screening. For quantification of IVS3 splicing activation, PCR cycle number was limited to 23 , and $\alpha^{-}{ }^{32} \mathrm{P}-\mathrm{dCTP}$ was included in the reaction. The PCR products were analyzed with $5 \%$ native polyacrylamide gels and the Typhoon PhosphorImager (GE Healthcare). Two sets of the double RNAi experiments were performed. In one set, $3 \mu \mathrm{g}+3 \mu \mathrm{g}$ of each dsRNA was used, and, in another set, $5 \mu \mathrm{g}+5 \mu \mathrm{g}$ of each dsRNA was used. Similar results were obtained with both sets.

\section{RNA EMSAs}

In a $30-\mu \mathrm{L}$ reaction, a trace amount $(\sim 10 \mathrm{fmol})$ of 69 -nt $\alpha-{ }^{32} \mathrm{P}-\mathrm{UTP}$ labeled P-element silencer RNA was incubated with the indicated protein in binding buffer $(50 \mathrm{mM}$ Tris- $\mathrm{HCl}$ at $\mathrm{pH} 7.4,150 \mathrm{mM}$ $\mathrm{KCl}, 2 \mathrm{mM} \mathrm{MgCl}$, $2 \mathrm{mM} \mathrm{DTT}, 0.1 \mathrm{mg} / \mathrm{mL}$ heparin) at room temperature for $30 \mathrm{~min}$. Twenty-five percent glycerol and bromophenol blue dye were added, and $10 \mu \mathrm{L}$ of each reaction was loaded onto $10 \%$ acrylamide, $1 \times \mathrm{TBE}$, and $5 \%$ glycerol gel and separated for $1.5 \mathrm{~h}$ at room temperature at $150 \mathrm{~V}$. The ${ }^{32} \mathrm{P}$-labeled RNA signal was detected using Fuji PhosphorImager screens scanned on a GE Healthcare Typhoon Imager and quantitated with ImageJ software. Curves were plotted, and binding constants were calculated using Prism software. For the hrp48 supershift gel-binding assay, $20 \mathrm{nM}$ hrp48 was added immediately after addition of the hrp36 or hrp38 proteins.

\section{Immobilized RNA pull-down assays}

NeutrAvidin agarose resin (Pierce) was washed with G60 binding buffer $(60 \mathrm{mM} \mathrm{KCl}, 20 \mathrm{mM}$ HEPES, $0.5 \mathrm{mM}$ EDTA, $0.5 \mathrm{mM}$ DTT), blocked with $0.1 \mathrm{mg} / \mathrm{mL}$ total yeast RNA and $0.1 \mathrm{mg} / \mathrm{mL}$ BSA for $30 \mathrm{~min}$ at $25^{\circ} \mathrm{C}$, and washed once with two column volumes of G60 buffer. Fifty micrograms of biotinylated RNA per milliliter of resin was incubated for $1 \mathrm{~h}$ at $4^{\circ} \mathrm{C}$ and washed five times with two column volumes of G60 buffer. In a $50-\mu \mathrm{L}$ reaction volume of G60 buffer, $10 \mu \mathrm{L}$ of RNA-bound resin was incubated with $200 \mathrm{nM}$ hrp36, $200 \mathrm{nM}$ hrp38, and the indicated concentrations of hrp48 or hrp48-RRM for $30 \mathrm{~min}$ at $25^{\circ} \mathrm{C}$. Reactions were washed four times with 10 column volumes of G60 buffer, $10 \mu \mathrm{L}$ of resin was resuspended in $20 \mu \mathrm{L}$ of SDS protein 
gel sample buffer and heated for $3 \mathrm{~min}$ at $75^{\circ} \mathrm{C}$, and proteins were separated on a $10 \%$ SDS-polyacrylamide gel and subjected to immunoblotting with the indicated antibodies.

\section{Immobilized MBP fusion protein pull-down assay}

Purified His6-MBP-TEV-hrp48 and His6-MBP-TEV-hrp48-RRM proteins were bound to Ni-sepharose high-performance resin (GE Healthcare), washed with $1 \mathrm{M} \mathrm{NaCl}$ to remove maltose from the MBP, and eluted with $500 \mathrm{mM}$ imidazole. His6-MBPhrp4GRD was purified from baculovirus-infected SF9 cell lysates on Ni-sepharose HisTrap (GE Healthcare) and eluted with 500 $\mathrm{mM}$ imidazole.

Amylose resin (New England Biolabs) was washed with G60 buffer, blocked with $0.1 \mathrm{mg} / \mathrm{mL}$ total yeast RNA and $0.1 \mathrm{mg} /$ $\mathrm{mL}$ BSA for $30 \mathrm{~min}$ at $25^{\circ} \mathrm{C}$, and washed three times with two column volumes of G60 buffer. One-hundred micrograms of His6MBP-TEV-hrp48 and His6-MBP-TEV-hrp48-GRD per milliliter of amylose resin were incubated for $4 \mathrm{~h}$ at $4^{\circ} \mathrm{C}$. One-hundred micrograms of His6-MBP-TEV-hrp48-RRM per milliliter of resin was incubated overnight at $4^{\circ} \mathrm{C}$. All samples were washed five times with two column volumes of G60 buffer. In a $50-\mu \mathrm{L}$ reaction volume of G60 buffer, $10 \mu \mathrm{L}$ of MBP-bound resin was incubated with $2.5 \mu \mathrm{L}$ of either wild-type RNA or L456 RNA for $10 \mathrm{~min}$ at $25^{\circ} \mathrm{C}$ and washed once with two column volumes of G60. The 10- $\mu \mathrm{L}$ MBP-RNA resin reactions were resuspended to $50 \mu \mathrm{L}$ and incubated with $200 \mathrm{nM}$ hrp36 or hrp38 for $30 \mathrm{~min}$ at $25^{\circ} \mathrm{C}$. Reactions were washed three times with 10 column volumes of G60, and $10 \mu \mathrm{L}$ of resin was resuspended in $20 \mu \mathrm{L}$ of SDS protein gel sample buffer heated for $3 \mathrm{~min}$ at $75^{\circ} \mathrm{C}$ and run on a $10 \%$ SDS-PAGE gel. Gels were subjected to immunoblotting with anti-hrp48, anti-hrp36, or anti-hrp38 antibodies.

\section{Acknowledgments}

We thank all members of the Rio laboratory for help and suggestions and for sharing reagents, and Yeon Lee for reading the manuscript. This work used the Vincent J. Coates Proteomics/ Mass Spectrometry Laboratory for mass spectrometry, supported in part by National Institutes of Health S10 Instrumentation grant S10RR025622. This work was supported by National Institutes of Health grants R01GM61987, R01GM094890, and R01GM097352. J.C.Y. was partially supported by post-doctoral fellowship PF-07-281-01-GMC from the American Cancer Society and F32 GM080943 from the National Institutes of Health. L. $\mathrm{H}$. prepared and analyzed RNA binding by purified recombinant proteins and performed RNA and protein pull-down assays. J.C. Y. prepared biochemical fractions of the P-element splicing silencer complex, performed gel filtration chromatography and RNA affinity purifications, prepared samples for mass spectrometry, and performed RNAi and splicing minigene reporter assays. L.A.K. assisted with mass spectrometry and analyzed and quantitated the mass spectrometry data. D.C.R. supervised the studies, interpreted data, and provided experimental input. All authors wrote the paper.

\section{References}

Adams MD, Tarng RS, Rio DC. 1997. The alternative splicing factor PSI regulates P-element third intron splicing in vivo. Genes Dev 11: 129-138.

Afonina E, Stauber R, Pavlakis GN. 1998. The human poly(A)binding protein 1 shuttles between the nucleus and the cytoplasm. J Biol Chem 273: 13015-13021.
Amarasinghe AK, MacDiarmid R, Adams MD, Rio DC. 2001. An in vitro-selected RNA-binding site for the $\mathrm{KH}$ domain protein PSI acts as a splicing inhibitor element. RNA 7: 1239-1253.

Barbosa-Morais NL, Irimia M, Pan Q, Xiong HY, Gueroussov S, Lee LJ, Slobodeniuc V, Kutter C, Watt S, Colak R, et al. 2012. The evolutionary landscape of alternative splicing in vertebrate species. Science 338: 1587-1593.

Behm-Ansmant I, Gatfield D, Rehwinkel J, Hilgers V, Izaurralde E. 2007. A conserved role for cytoplasmic poly(A)-binding protein 1 (PABPC1) in nonsense-mediated mRNA decay. EMBO J 26: $1591-1601$.

Black DL. 2003. Mechanisms of alternative pre-messenger RNA splicing. Annu Rev Biochem 72: 291-336.

Blanchette M, Chabot B. 1999. Modulation of exon skipping by high-affinity hnRNP A1-binding sites and by intron elements that repress splice site utilization. EMBO J 18: 1939-1952.

Blanchette M, Green RE, MacArthur S, Brooks AN, Brenner SE, Eisen MB, Rio DC. 2009. Genome-wide analysis of alternative pre-mRNA splicing and RNA-binding specificities of the Drosophila hnRNP A/B family members. Mol Cell 33: 438-449.

Bonnal S, Vigevani L, Valcarcel J. 2012. The spliceosome as a target of novel antitumour drugs. Nat Rev Drug Discov 11: 847-859.

Brune C, Munchel SE, Fischer N, Podtelejnikov AV, Weis K. 2005. Yeast poly(A)-binding protein Pab1 shuttles between the nucleus and the cytoplasm and functions in mRNA export. RNA 11: 517-531.

Chain AC, Zollman S, Tseng JC, Laski FA. 1991. Identification of a cis-acting sequence required for germ line-specific splicing of the P element ORF2-ORF3 intron. Mol Cell Biol 11: 1538-1546.

Cociorva D, Tabb DL, Yates JR. 2007. Validation of tandem mass spectrometry database search results using DTASelect. Curr Protoc Bioinformatics 16: 13.4.1-13.4.14.

Cooper TA, Wan L, Dreyfuss G. 2009. RNA and disease. Cell 136: 777-793.

de Melo Neto OP, Standart N, Martins de Sa C. 1995. Autoregulation of poly(A)-binding protein synthesis in vitro. Nucleic Acids Res 23: 2198-2205.

Dignam JD, Lebovitz RM, Roeder RG. 1983. Accurate transcription initiation by RNA polymerase II in a soluble extract from isolated mammalian nuclei. Nucleic Acids Res 11: 1475-1489.

Dreyfuss G, Matunis MJ, Pinol-Roma S, Burd CG. 1993. hnRNP proteins and the biogenesis of mRNA. Annu Rev Biochem 62: 289-321.

Dunn EF, Hammell CM, Hodge CA, Cole CN. 2005. Yeast poly(A)binding protein, $\mathrm{Pab} 1$, and $\mathrm{PAN}$, a poly(A) nuclease complex recruited by Pab1, connect mRNA biogenesis to export. Genes Dev 19: 90-103.

Gilbert WV, Zhou K, Butler TK, Doudna JA. 2007. Cap-independent translation is required for starvation-induced differentiation in yeast. Science 317: 1224-1227.

Hammond LE, Rudner DZ, Kanaar R, Rio DC. 1997. Mutations in the hrp48 gene, which encodes a Drosophila heterogeneous nuclear ribonucleoprotein particle protein, cause lethality and developmental defects and affect P-element third-intron splicing in vivo. Mol Cell Biol 17: 7260-7267.

Han TW, Kato M, Xie S, Wu LC, Mirzaei H, Pei J, Chen M, Xie Y, Allen J, Xiao G, et al. 2012. Cell-free formation of RNA granules: bound RNAs identify features and components of cellular assemblies. Cell 149: 768-779.

Haynes SR, Johnson D, Raychaudhuri G, Beyer AL. 1991. The Drosophila Hrb87F gene encodes a new member of the A and B hnRNP protein group. Nucleic Acids Res 19: 25-31. 
Hosoda N, Lejeune F, Maquat LE. 2006. Evidence that poly(A) binding protein $\mathrm{C} 1$ binds nuclear pre-mRNA poly(A) tails. Mol Cell Biol 26: 3085-3097.

Huelga SC, Vu AQ, Arnold JD, Liang TY, Liu PP, Yan BY, Donohue JP, Shiue L, Hoon S, Brenner S, et al. 2012. Integrative genome-wide analysis reveals cooperative regulation of alternative splicing by hnRNP proteins. Cell Rep 1: 167-178.

Ishihama Y, Oda Y, Tabata T, Sato T, Nagasu T, Rappsilber J, Mann M. 2005. Exponentially modified protein abundance index (emPAI) for estimation of absolute protein amount in proteomics by the number of sequenced peptides per protein. Mol Cell Proteomics 4: 1265-1272.

Kato M, Han TW, Xie S, Shi K, Du X, Wu LC, Mirzaei H, Goldsmith EJ, Longgood J, Pei J, et al. 2012. Cell-free formation of RNA granules: low complexity sequence domains form dynamic fibers within hydrogels. Cell 149: 753-767.

Kwon I, Kato M, Xiang S, Wu L, Theodoropoulos P, Mirzaei H, Han T, Xie S, Corden JL, McKnight SL. 2013. Phosphorylation-regulated binding of RNA polymerase II to fibrous polymers of low-complexity domains. Cell 155: 1049-1060.

Labourier E, Adams MD, Rio DC. 2001. Modulation of P-element pre-mRNA splicing by a direct interaction between PSI and U1 snRNP 70K protein. Mol Cell 8: 363-373.

Laski FA, Rubin GM. 1989. Analysis of the cis-acting requirements for germ-line-specific splicing of the P-element ORF2-ORF3 intron. Genes Dev 3: 720-728.

Laski FA, Rio DC, Rubin GM. 1986. Tissue specificity of Drosophila $\mathrm{P}$ element transposition is regulated at the level of mRNA splicing. Cell 44: 7-19.

Lasko P. 2000. The Drosophila melanogaster genome: translation factors and RNA binding proteins. J Cell Biol 150: F51-F56.

Lee Y, Rio DC. 2015. Mechanisms and regulation of alternative pre-mRNA splicing. Annu Rev Biochem 84: 291-323.

Lemay JF, Lemieux C, St-Andre O, Bachand F. 2010. Crossing the borders: poly(A)-binding proteins working on both sides of the fence. RNA Biol 7: 291-295.

Lim F, Downey TP, Peabody DS. 2001. Translational repression and specific RNA binding by the coat protein of the Pseudomonas phage PP7. J Biol Chem 276: 22507-22513.

Liu S, Cheng C. 2013. Alternative RNA splicing and cancer. Wiley Interdiscip Rev RNA 4: 547-566.

Majumdar S, Rio DC. 2015. P transposable elements in Drosophila and other eukaryotic organisms. Microbiol Spectr 3.

Mangus DA, Evans MC, Jacobson A. 2003. Poly(A)-binding proteins: multifunctional scaffolds for the post-transcriptional control of gene expression. Genome Biol 4: 223.

Matunis EL, Matunis MJ, Dreyfuss G. 1992a. Characterization of the major hnRNP proteins from Drosophila melanogaster. I Cell Biol 116: 257-269.

Matunis MJ, Matunis EL, Dreyfuss G. 1992b. Isolation of hnRNP complexes from Drosophila melanogaster. I Cell Biol 116: 245-255.

Mayeda A, Munroe SH, Caceres JF, Krainer AR. 1994. Function of conserved domains of hnRNP Al and other hnRNP A/B proteins. EMBO J 13: 5483-5495.

McDonald WH, Tabb DL, Sadygov RG, MacCoss MJ, Venable J, Graumann J, Johnson JR, Cociorva D, Yates JR III. 2004. MS1, MS2, and SQT-three unified, compact, and easily parsed file formats for the storage of shotgun proteomic spectra and identifications. Rapid Commun Mass Spectrom 18: 21622168.

Merkin J, Russell C, Chen P, Burge CB. 2012. Evolutionary dynamics of gene and isoform regulation in Mammalian tissues. Science 338: 1593-1599.
Misra S, Rio DC. 1990. Cytotype control of Drosophila P element transposition: the $66 \mathrm{kd}$ protein is a repressor of transposase activity. Cell 62: 269-284.

O'Hare K, Rubin GM. 1983. Structures of P transposable elements and their sites of insertion and excision in the Drosophila melanogaster genome. Cell 34: 25-35.

Okunola HL, Krainer AR. 2009. Cooperative-binding and splicing-repressive properties of hnRNP A1. Mol Cell Biol 29: 5620-5631.

Padgett RA. 2012. New connections between splicing and human disease. Trends Genet 28: 147-154.

Pan Q, Shai O, Lee LJ, Frey BJ, Blencowe BJ. 2008. Deep surveying of alternative splicing complexity in the human transcriptome by high-throughput sequencing. Nat Genet 40: 1413-1415.

Paoletti AC, Parmely TJ, Tomomori-Sato C, Sato S, Zhu D, Conaway RC, Conaway JW, Florens L, Washburn MP. 2006. Quantitative proteomic analysis of distinct mammalian Mediator complexes using normalized spectral abundance factors. Proc Natl Acad Sci 103: 18928-18933.

Park SK, Venable JD, Xu T, Yates JR III. 2008. A quantitative analysis software tool for mass spectrometry-based proteomics. Nat Methods 5: 319-322.

Peng J, Elias JE, Thoreen CC, Licklider LJ, Gygi SP. 2003. Evaluation of multidimensional chromatography coupled with tandem mass spectrometry (LC/LC-MS/MS) for large-scale protein analysis: the yeast proteome. J Proteome Res 2: 43-50.

Reed R, Hurt E. 2002. A conserved mRNA export machinery coupled to pre-mRNA splicing. Cell 108: 523-531.

Rio DC. 1988. Accurate and efficient pre-mRNA splicing in Drosophila cell-free extracts. Proc Natl Acad Sci 85: 29042908.

Rio DC. 2002. P transposable elements in Drosophila melanogaster. In Mobile DNA II (ed. Craig NL, et al.), pp. 484-518. Amer Society for Microbiology, Washington, DC.

Rio DC, Laski FA, Rubin GM. 1986. Identification and immunochemical analysis of biologically active Drosophila P element transposase. Cell 44: 21-32.

Roche SE, Schiff M, Rio DC. 1995. P-element repressor autoregulation involves germ-line transcriptional repression and reduction of third intron splicing. Genes Dev 9: 1278-1288.

Schwartz JC, Wang X, Podell ER, Cech TR. 2013. RNA seeds higher-order assembly of FUS protein. Cell Rep 5: 918-925.

Scott LM, Rebel VI. 2013. Acquired mutations that affect premRNA splicing in hematologic malignancies and solid tumors. J Natl Cancer Inst 105: 1540-1549.

Siebel CW, Rio DC. 1990. Regulated splicing of the P transposable element third intron in vitro: somatic repression. Science 248: 1200-1208.

Siebel CW, Fresco LD, Rio DC. 1992. The mechanism of somatic inhibition of $\mathrm{P}$ element pre-mRNA splicing: multi-protein complexes at an exon pseduo-5' splice site control U1 snRNA binding. Genes Dev 3: 720-728.

Siebel CW, Kanaar R, Rio DC. 1994. Regulation of tissue-specific P-element pre-mRNA splicing requires the RNA-binding protein PSI. Genes Dev 8: 1713-1725.

Siebel CW, Admon A, Rio DC. 1995. Soma-specific expression and cloning of PSI, a negative regulator of $\mathrm{P}$ element premRNA splicing. Genes Dev 9: 269-283.

Singh RK, Cooper TA. 2012. Pre-mRNA splicing in disease and therapeutics. Trends Mol Med 18: 472-482.

Tabb DL, McDonald WH, Yates JR III. 2002. DTASelect and Contrast: tools for assembling and comparing protein identifications from shotgun proteomics. J Proteome Res 1: 21-26. 
Tweedie S, Ashburner M, Falls K, Leyland P, McQuilton P, Marygold S, Millburn G, Osumi-Sutherland D, Schroeder A, Seal $\mathrm{R}$, et al. 2009. FlyBase: enhancing Drosophila gene ontology annotations. Nucleic Acids Res 37: D555-D559.

Wahl MC, Will CL, Luhrmann R. 2009. The spliceosome: design principles of a dynamic RNP machine. Cell 136: 701-718.

Wang ET, Sandberg R, Luo S, Khrebtukova I, Zhang L, Mayr C, Kingsmore SF, Schroth GP, Burge CB. 2008. Alternative isoform regulation in human tissue transcriptomes. Nature 456: 470-476.

Washburn MP, Wolters D, Yates JR III. 2001. Large-scale analysis of the yeast proteome by multidimensional protein identification technology. Nat Biotechnol 19: 242-247.

Xu T, Venable JD, Kyu Park S, Cociorva D, Lu B, Liao L, Wohlschlegel J, Hewel J, Yates JR III. 2006. ProLuCID, a fast and sen- sitive tandem mass spectra-based protein identification program. Mol Cell Proteomics 5: S174.

Yeo GW, Van Nostrand E, Holste D, Poggio T, Burge CB. 2005. Identification and analysis of alternative splicing events conserved in human and mouse. Proc Natl Acad Sci 102: 2850-2855.

Zhang J, Manley JL. 2013. Misregulation of pre-mRNA alternative splicing in cancer. Cancer Discov 3: 1228-1237.

Zhou Z, Reed R. 2003. Purification of functional RNA-protein complexes using MS2-MBP. Curr Protoc Mol Biol 63: 27.3.1-27.3.7.

Zhu J, Mayeda A, Krainer AR. 2001. Exon identity established through differential antagonism between exonic splicing silencer-bound hnRNP A1 and enhancer-bound SR proteins. Mol Cell 8: 1351-1361. 


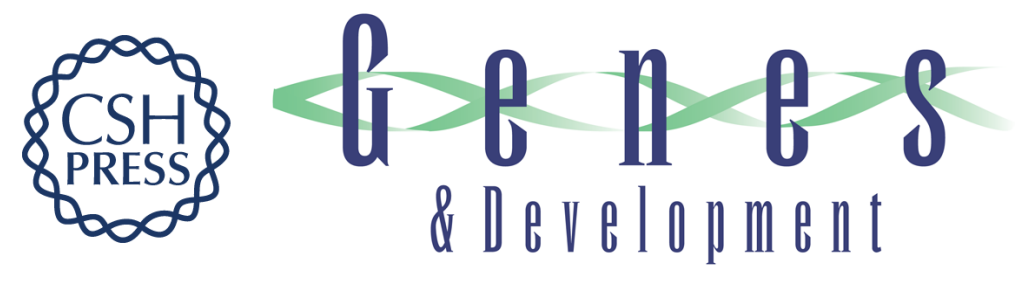

\title{
Biochemical identification of new proteins involved in splicing repression at the Drosophila P-element exonic splicing silencer
}

\author{
Lucas Horan, Jiro C. Yasuhara, Lori A. Kohlstaedt, et al.
}

Genes Dev. 2015, 29:

Access the most recent version at doi:10.1101/gad.268847.115

\section{Supplemental http://genesdev.cshlp.org/content/suppl/2015/11/06/29.21.2298.DC1 \\ Material}

References This article cites 69 articles, 28 of which can be accessed free at:

http://genesdev.cshlp.org/content/29/21/2298.full.html\#ref-list-1

Creative This article is distributed exclusively by Cold Spring Harbor Laboratory Press for the first

Commons six months after the full-issue publication date (see

License http://genesdev.cshlp.org/site/misc/terms.xhtml). After six months, it is available under a Creative Commons License (Attribution-NonCommercial 4.0 International), as described at http://creativecommons.org/licenses/by-nc/4.0/.

Email Alerting Receive free email alerts when new articles cite this article - sign up in the box at the top Service right corner of the article or click here.

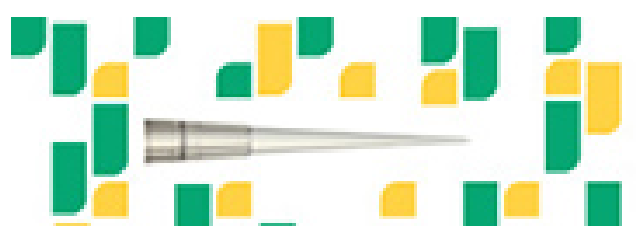

Focused on your science. 